\title{
Special issue: The 5th International Conference of the CIS Countries, St Petersburg, August 27-31, 2018
}

\section{Sol-Gel Synthesis and Research on Inorganic Compounds, Hybrid Functional Materials and Disperse Systems}

\section{Olga A. Shilova ${ }^{1} \cdot$ Vadim G. Kessler $^{2}$}

Published online: 18 October 2019

(c) Springer Science+Business Media, LLC, part of Springer Nature 2019

This issue of the journal presents contributions from the 5 th International Sol-Gel Conference of CIS countries. It is a traditional biennial event held alternately in turn in Russia, and then in one of the CIS countries. The fifth, anniversary CIS Sol-Gel 2018 conference was carried out in the end of August 2018 in St. Petersburg. Its major organizer was the Institute of Silicate Chemistry of the Russian Academy of Sciences, a major research center in this field in the NorthWest of Russia and the initiator of this conference series. The conference agenda covered theoretical aspects of the sol-gel process, challenges in the sol-gel synthesis, and preparation of nanoparticles, films, coatings and membranes, hybrid inorganic and organic-inorganic composites, xerogels, glass and bulk ceramic materials. Strong focus was set on the use of sol-gel synthesis in the field of environmental protection, agriculture, and biomedicine.

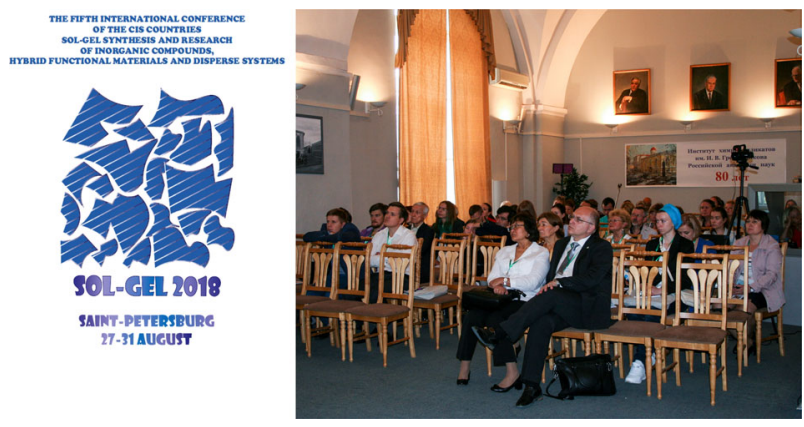

Vadim G. Kessler

vadim.kessler@slu.se

1 Institute of Silicate Chemistry of Russian Academy of Science, Sain-Petersburg, Russia

2 Department of Molecular Sciences, Swedish University of Agricultural Sciences, Uppsala, Sweden 